MATEC Web of Conferences 2, 02002 (2012)

DOI: $10.1051 /$ matecconf $/ 20120202002$

C Owned by the authors, published by EDP Sciences, 2012

\title{
Use of metakaolin in grouts intended for soil nailing
}

\author{
M. Trinh ${ }^{1,2}$, M.Cyr $^{1}$, B. Husson ${ }^{1}$, G. Casaux-Ginestet ${ }^{1}$ and P. Robit ${ }^{2}$ \\ ${ }^{1}$ Université de Toulouse, INSA/UPS, LMDC (Laboratoire Matériaux et Durabilité des \\ Constructions), Toulouse, France \\ ${ }^{2}$ GTS (Travaux Géotechniques et Sécurisation), Domène, France
}

\begin{abstract}
The aim of this work was to carry out a feasibility study to evaluate the pertinence of using metakaolin in grout intended for soil nailing. After a first step of grout optimisation based on technical and environmental constraints, an in-situ study was performed to evaluate the compatibility of metakaolin with this kind of application. This part highlights the minimum performance levels necessary if grout is to fulfil its role of transferring stresses between soil and nail.
\end{abstract}

\section{Introduction}

Soil nailing has been in common use since the 70's to treat unstable natural soil slopes, or to stabilize retaining walls or existing fill slopes (embankments). The technique involves the insertion of reinforcing elements such as steel bars into the slope. The bars are usually installed in pre-drilled holes and then fixed into place using a cement grout. In France, two national projects (Clouterre I and II, [1] and [2]) defined the state of the art of such practices, from the theoretical background to the design procedures.

Although many works have already addressed the subject, progress is still possible on the materials used in the field, since relatively few reports can be found on the optimisation of the cement grout used for soil nails. The role of grout is multiple: it offers a primary function of transferring stresses between the ground and the soil-nail reinforcement and it also provides a nominal level of corrosion protection for the reinforcement.

The current practice in several projects is to use grouts made of cement (e.g. CEM I 52.5) and water only, at a water-cement ratio around 0.5. This choice leads to high compressive strength (maybe overdesigned), but is nowadays unacceptable regarding $\mathrm{CO}_{2}$ emission, since the current tendency is to improve the $\mathrm{CO}_{2}$ balance in construction.

Metakaolin (MK), which is a pozzolanic material obtained from the calcination of natural clay (kaolinite), could be a promising option that might help to minimize the $\mathrm{CO}_{2}$ problem, since it reduces $\mathrm{CO}_{2}$ emission by a factor of 10 compared to Portland cement [3]. Metakaolin is not often used in grout applications because it sometimes leads to an increase in water demand [4], incompatible with applications for which the rheology must be controlled. However, new forms of MK, such as flash metakaolins [5], show limited increases in water demands, allowing their possible use in soil nailing applications.

The aim of this paper is to present a feasibility study evaluating the pertinence of using MK in grout intended for soil nailing. After a first step of grout optimisation based on technical and 
environmental constraints, an in-situ study was performed to evaluate the compatibility of MK with this kind of application. This part highlights the minimum performance that grout needs to fulfil its role of transferring stresses between soil and nail.

\section{Materials and methods}

The cement used was a standard CEM I $52.5 \mathrm{~N}$ according to EN 197-1 (Table 1). The metakaolin (Table 1) came from Argeco Development and has been characterized elsewhere [3]. It was composed of an amorphous phase and quartz. The specific surface (BET) was $14 \mathrm{~m}^{2} / \mathrm{g}$. The quartz sand, which had a particle size ranging between 1 and $800 \mu \mathrm{m}$, contained around $10 \%$ of kaolinite.

Table 1. Chemical composition of materials.

\begin{tabular}{|c|c|c|c|c|c|c|c|c|c|}
\hline \% by mass & $\mathrm{SiO}_{2}$ & $\mathrm{Al}_{2} \mathrm{O}_{3}$ & $\mathrm{Fe}_{2} \mathrm{O}_{3}$ & $\mathrm{CaO}$ & $\mathrm{MgO}$ & $\mathrm{SO}_{3}$ & $\mathrm{~K}_{2} \mathrm{O}$ & $\mathrm{Na}_{2} \mathrm{O}$ & LOI \\
\hline CEM I 52.5 N & 19.9 & 5.5 & 2.4 & 64.0 & 1.9 & 3.1 & 0.5 & 0.1 & 1.7 \\
\hline MK & 67.1 & 26.8 & 2.6 & 1.1 & 0.1 & --- & 0.1 & 0.01 & 0.8 \\
\hline
\end{tabular}

Grouts were prepared using a turbo-type mixer with a $65-\mathrm{mm}$-diameter head. They were mixed for $10 \mathrm{~min}$ at a controlled speed of $2500 \mathrm{rpm}$. The flow time was measured $1 \mathrm{~min}$ after the end of mixing by Marsh cone (nozzle diameter of $4.75 \mathrm{~mm}$ ) according to standard NF P 18-358. The stability of the grouts was evaluated using a decantation test (NF P 18-359) 4 min after mixing. The test measured the ratio of the water volume collected after 2 hours at the top of a test tube filled with grout relative to the total initial volume. Compressive strength tests were performed at 28 days on prismatic specimens of dimensions $4 \times 4 \times 16 \mathrm{~cm}$ according to standard EN 196-1. After casting, the samples were kept in the moulds for $24 \mathrm{~h}$ at $95 \% \mathrm{RH}$ and $20^{\circ} \mathrm{C}$, then were demoulded and immersed in water at $20^{\circ} \mathrm{C}$ until the age of test.

Pull-out tests were carried out according standard XP P94-444 between December 2010 and March 2011, $200 \mathrm{~m}$ inside the gallery of a quarry (temperature range: $+2^{\circ} \mathrm{C} /+8^{\circ} \mathrm{C}$ ). The holes, 115 $\mathrm{mm}$ in diameter and $1.2 \mathrm{~m}$ long, were drilled inside massive calcareous rock. The steel bars $\mathrm{S} 670$ (diameter $43 \mathrm{~mm}$ and yield strength $670 \mathrm{MPa}$ ) were sealed by gravity for a length of $1 \mathrm{~m}$ (Figure 1).

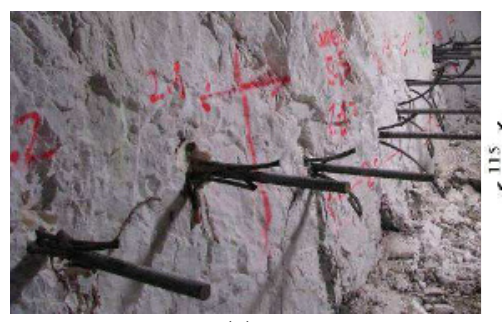

(a)

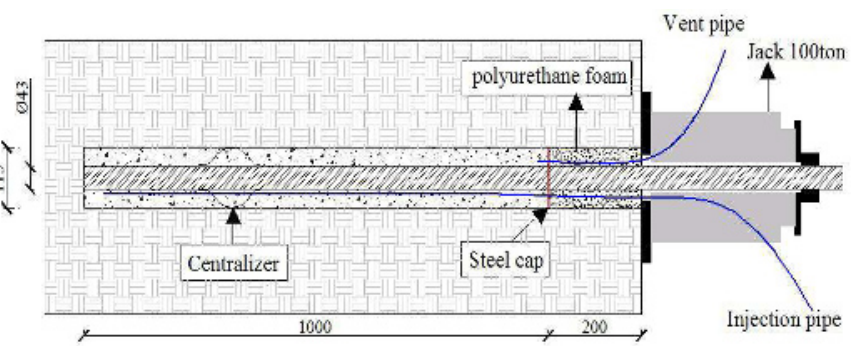

(b)

Fig. 1. Photo and schema of soil nails in-situ. Dimensions are in $\mathrm{mm}$. 


\section{Results and discussion}

The experimental programme was divided into two steps: a first step for the parametric study of the formulation parameters of the grouts, followed by an in-situ programme of pull-out tests to evaluate the performance of the grouts designed.

\subsection{Grout design in laboratory}

The feasibility of using metakaolin in grouts was studied in the laboratory. The main technical constraints existing for this kind of material concerned grout rheology, stability and compressive strength.

\subsubsection{Rheology}

The rheological properties should be chosen to allow the grout to fill the drilled hole containing the nail (steel bar) without leaving any voids. The continuity of the grout ensures transmission of the stress between the soil and the bar, and could help to protect the bar against corrosion. However, the fluidity of the grout should be limited in order to guarantee a minimum of stability before setting. The recommended flowing times, measured using a Marsh cone, range between 50 and 80 seconds [1].

\subsubsection{Stability}

The stability of the grout before setting is primordial in order to avoid heterogeneity in the material, caused by segregation and bleeding. Heterogeneity could favour localised weakness, impeding the grout from playing its role. The height of water measured at the top of the cylinder should not exceed $3 \%$ in most applications (industrial constraint).

\subsubsection{Compressive strength}

The compressive strength is the easiest mechanical parameter to measure on grout. It must be sufficient to ensure the transmission of the stress between the soil and the bar, without being the weak link of the system. Three out of the four main possible points of failure when nails are subjected to a tensile force are related to the grout (Figure 2): soil-grout interface (A), bulk grout (B), and grout-bar interface (C). The fracture of the steel bar (D) occurs principally in very good soils, when the surface of contact between the soil and the bar is important, or when the grout penetrates deeply into the soil (bulb of grout). The soil-grout interface (A) mostly depends on the quality of the soil in place, the friction at the interface often being described by a Mohr-Coulomb criterion [6]. Usually the grout is designed to avoid failure in configurations $\mathrm{B}$ and $\mathrm{C}$, but little literature exists on the subject. The recommended values, when specified, can vary from 20 to $30 \mathrm{MPa}$ [7].

In addition to these technical constraints, the grouts were designed according to supplementary requirements. The formulation specifications included:

- a decrease in the cement content, for environmental and economic reasons

- the use of metakaolin as pozzolanic material to compensate for the decrease in cement content

- the use of fine sand for environmental and economic reasons

- a choice of water content compatible with the technical constraints 


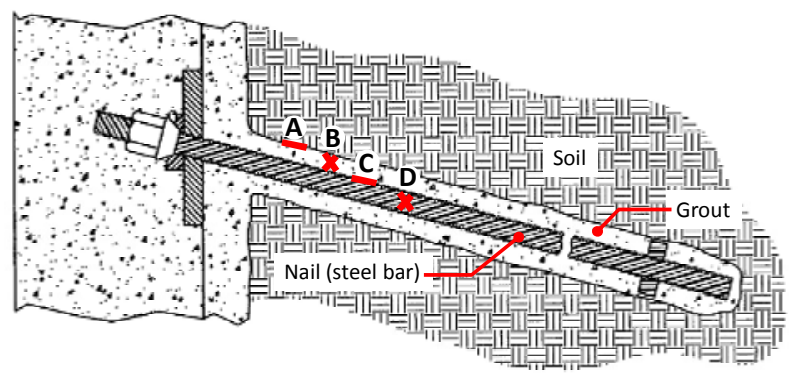

Fig. 2. Schematic diagram of soil nail, representing the possible points of failure: soil-grout interface (A), bulk grouts (B), grout-bar interface (C) and steel bar (D).

In order to fulfil these requirements, a mixture plan was designed and carried out. The formulation parameters varied within the limits given in Table 2. 36 mixtures were tested for flowing time, stability and compressive strength

Table 2. Grout formulation (limits of the mixture plan).

\begin{tabular}{|l|l|}
\hline Cement CEM I 52.5 N (\%, by mass) & $40 \%, 50 \%, 60 \%$ \\
\hline Metakaolin (\%, by mass) & $30 \%, 40 \%, 50 \%, 60 \%$ \\
\hline Fine sand $(\%$, by mass) & $0 \%, 10 \%, 20 \%, 30 \%$ \\
\hline Water content (expressed as volumetric solid content) & $0.38,0.39,0.40$ \\
\hline
\end{tabular}

The following trends can be drawn from the results of the 36 grouts:

The stability satisfied the requirements, since less than $2 \%$ of decantation was obtained for the 36 mixtures. The general tendency was for the stability to be slightly improved for high solid concentrations and high metakaolin contents.

The flowing time (Figure 3) increased when:

- the volumetric solid fraction increased

- the cement content decreased

- the proportion of MK increased, so the sand content decreased
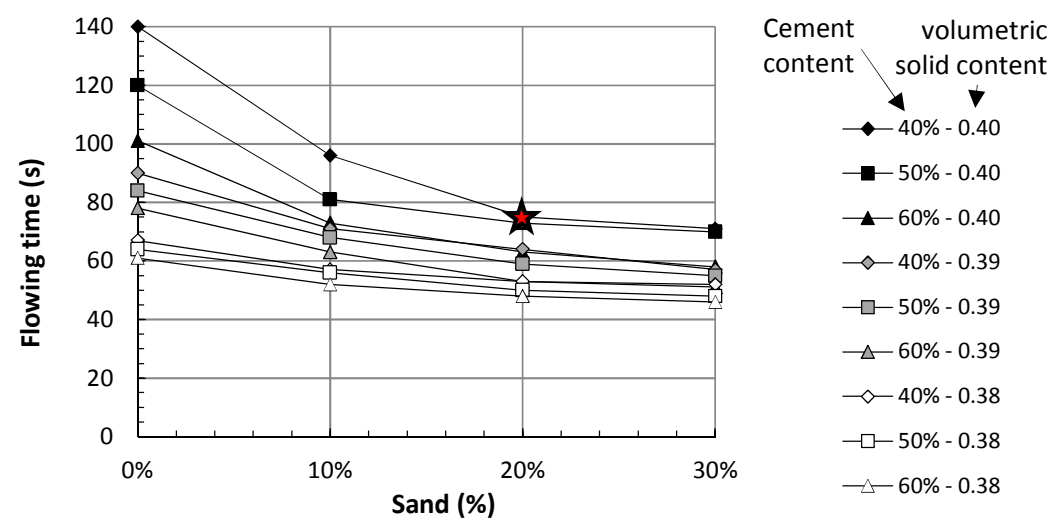

Fig. 3. Flowing time (Marsh cone) of grouts, depending on the composition parameters. Star: grout used for tests in situ. 
The compressive strength (Figure 4) increased when:

- the volumetric solid fraction increased

- the cement content increased

- for a given water content, the metakaolin content increased
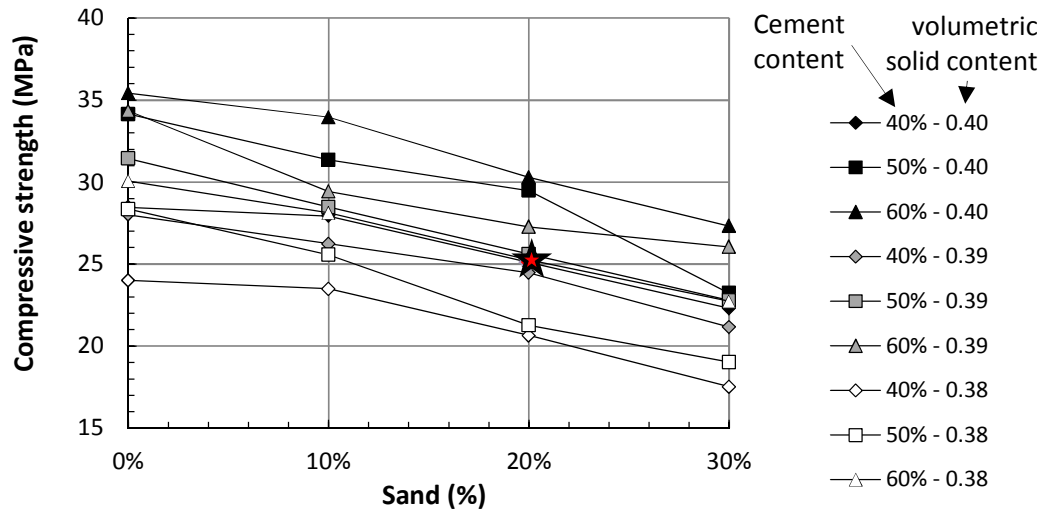

Fig. 4. 28d-compressive strength of grouts, depending on the composition parameters. Star: grout used for in situ tests.

From a technical point of view, large cement content gave the highest strength but also the highest flowing times. Moreover, these mixtures led to high $\mathrm{CO}_{2}$ release (Figure 5).

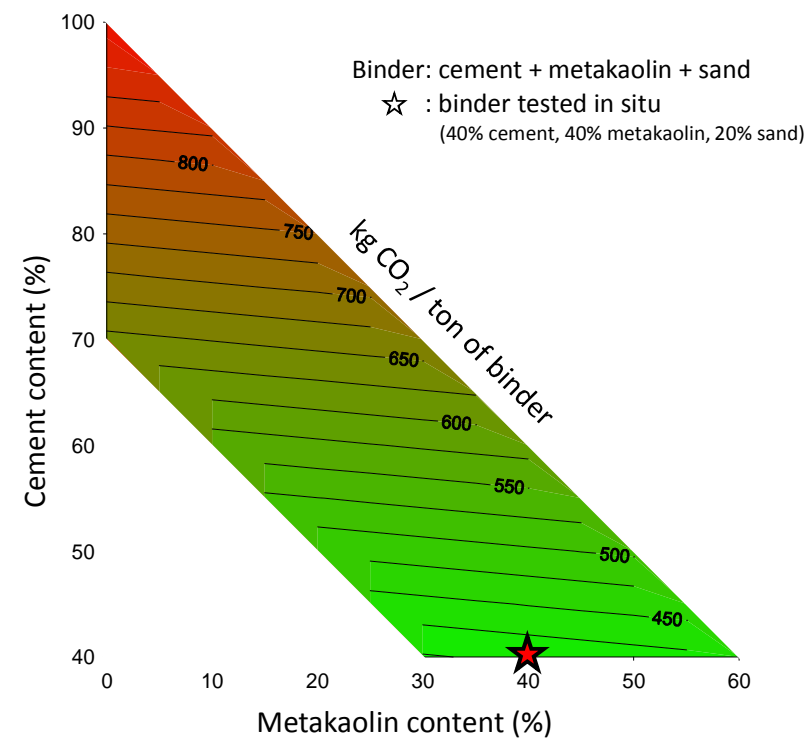

Fig. 5. iso-curves of $\mathrm{CO}_{2}$ release of binders composed of cement, metakaolin and sand.

Considering that grouts having low cement content (40\%) could reach at least $20 \mathrm{MPa}$ (Figure 4: preferably for not more that $20 \%$ of sand, and for high volumetric solid content, i.e. low water-binder ratio), environmental constraints (Figure 5) led us to favour high replacement rates of cement by metakaolin, since $\mathrm{MK}$ releases 10 times less $\mathrm{CO}_{2}$ than Portland cement [3]. 
The grout chosen for in-situ tests is marked by a star (Figures 3, 4 and 5) and contained $40 \%$ of cement, $40 \%$ of metakaolin and $20 \%$ of sand. The grout had a flowing time of $75 \mathrm{~s}, 28 \mathrm{~d}$-compressive strength of $25 \mathrm{MPa}$ and $\mathrm{CO}_{2}$ release of $406 \mathrm{~kg}$ of $\mathrm{CO}_{2} /$ ton of binder (compared to $916 \mathrm{~kg}$ of $\mathrm{CO}_{2} / \mathrm{ton}$ of Portland cement).

\subsection{In-situ pull-out tests}

The second step of the experimental programme was to evaluate the in-situ performance of a grout by using pull-out tests. The nails were sealed in massive rock in order to provoke failure in the grout or the steel bar, instead of at the soil-grout interface as is usually observed (in most applications, the weak link is at the soil-grout interface, the shear strength being limited by the properties of the soil). Two grout mixtures were tested (Table 3): a reference containing cement only and a MK-grout composed of cement, metakaolin and sand. The results for pull-out forces $\left(P_{\text {failure }}\right)$ and mobilized pull-out resistance of a soil-nail ( $q_{s}$ in $\mathrm{kPa}$, according to equation 1$)$ are given in Figure 6, according to grout strength.

$$
q_{s}=\frac{P_{\text {failure }}}{\pi \times D_{\text {hole }} \times L_{\text {sealed }}}
$$

Where $P_{\text {failure }}$ is the pull-out force $(\mathrm{kN})$ at the end of the test (failure of the nail, due to either the grout or the steel bar $-90 \%$ of the yield stress), $D_{\text {hole }}$ is the diameter (in m) of the hole drilled, and $L_{\text {sealed }}$ is the length $(\mathrm{m})$ of the nail sealed in the rock by the grout.

Table 3. Grout compositions for in-situ pull-out tests.

\begin{tabular}{|l|c|c|c|c|c|}
\hline & Cement & Metakaolin & Sand & water/(C+MK) (mass) & volumetric solid content \\
\hline Reference & $100 \% *$ & --- & --- & 0.50 & 0.39 \\
\hline MK-grout & $40 \%$ & $40 \%$ & $20 \%$ & 0.68 & 0.40 \\
\hline
\end{tabular}

* CEM I 52.5 PM ES Vicat

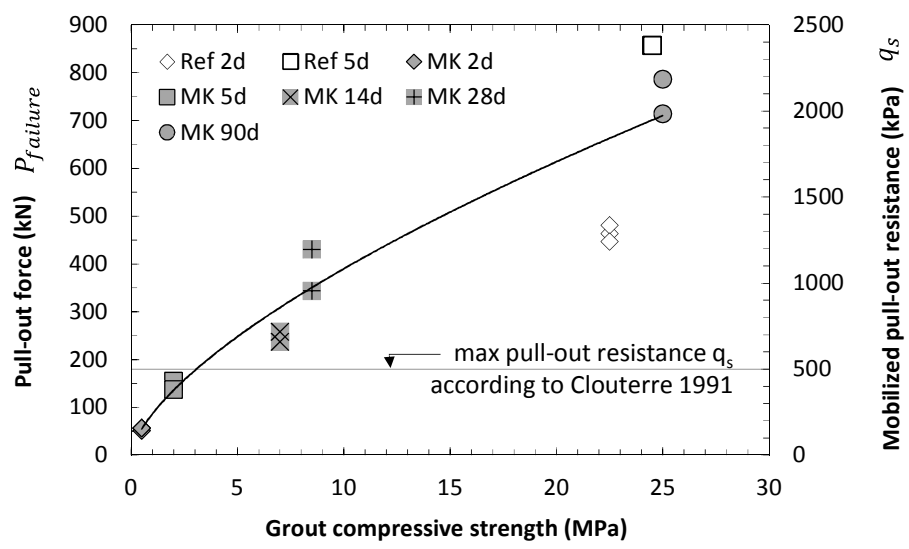

Fig. 6. Results of in-situ pull-out tests, using reference and metakaolin grouts. 
It can be seen that:

- reference grout had higher compressive strengths than MK-grout. This could be partially explained by the increased water-binder ratio of MK-grouts (Table 3). Consequently pullout forces were higher.

- reference grout seemed to be overdesigned, however, when compared to the maximal pullout resistance qs given by the Clouterre recommendations (which does not exceed $500 \mathrm{kPa}$ ) [1].

- a relationship existed between $q_{s}$ and compressive strength of the grout.

- MK-grout reached sufficient strength at 14 days (at temperature $2-8^{\circ} \mathrm{C}$ ) to mobilize the required pull-out resistance. A shorter time could be expected at normal temperature.

- the in situ strengths of the grouts were much lower than those measured in the laboratory, due to very low temperatures in the quarry at the period of the tests (temperature range: $\left.+2^{\circ} \mathrm{C} /+8^{\circ} \mathrm{C}\right)$.

\section{Conclusion}

The aim of this study was to evaluate the feasibility of using metakaolin in grout intended for soil nailing applications. The main conclusions that can be drawn are that metakaolin can effectively be used, since:

- MK improves the environmental balance of grouts

- Although MK led to a decrease in mechanical performance levels due to the strong diminution of cement content (-60\%), it appears that MK grouts respected the technical constraints inherent in this kind of applications, as confirmed by in-situ pull-out tests.

- Contrary to usual recommendations which often lead to impose grouts in the range 20-30 $\mathrm{MPa}$, it seems that most in situ requirements (i.e. $q_{s}<500 \mathrm{kPa}$, which represents $90 \%$ of the missions) could be satisfied using $5 \mathrm{MPa}$-grouts.

\section{Acknowledgements}

The authors are very grateful to GTS Travaux Géotechniques et Sécurisation and the Association Nationale de la Recherche Technique (ANRT) for supporting the present research.

\section{References}

1. Projet national Clouterre, Presses de l'école nationale des Ponts et Chaussées (ENPC), France, 1991.

2. Projet national Clouterre II, Presses de l'école nationale des Ponts et Chaussées (ENPC), France, 2002.

3. R. San Nicolas, Approche performantielle des bétons avec métakaolins obtenus par calcination flash, Ph.D. Thesis, University Paul Sabatier, France, 2011.

4. B. B. Sabir, S. Wild and J. Bai, Metakaolin and calcined clays as pozzolans for concrete: a review, Cement and Concrete Composites, 23 (6) (2001), 441-454.

5. F. Cassagnabère, Produits préfabriqués en béton filé: vers l'amélioration des performances du matériau pour mieux gérer le procédé de production, Ph.D. Thesis, University Paul Sabatier, France, 2007.

6. Y.D. Zhou, C.Y. Cheuk, L.G. Tham, An embedded bond-slip model for finite element modelling of soil-nail interaction, Computers and Geotechnics 36 (2009), 1090-1097.

7. Turner, J.B., Influence of grout mix design and placement procedures on the integrity of installed soil nails, M.Sc. Thesis, Texas Tech University, USA, 2004. 